\title{
Nitrosamine (and/or Irbesartan) Induced Large Plaque Parapsoriasis and Urothelial Carcinoma: First Report in the Medical Literature!
}

\author{
Tchernev G*, Oliveira N, Kandathil LJ \\ Onkoderma, Policlinic for Dermatology, Venereology and Dermatologic Surgery, Sofia, Bulgaria
}

\begin{abstract}
Received: July 30, 2021; Accepted: August 02, 2021; Published: August 04, 2021
*Corresponding author: GeorgiTchernev, Onkoderma, Clinic for Dermatology, Venereology and Dermatologic Surgery, General Skobelev, E-mail: georgi_tchernev@yahoo.de
\end{abstract}

A presenting case of a 64-year-old gentleman with a complaint of disseminated skin rash on the trunk, upper and lower limbs. He was diagnosed with type II hypertension in January 2017 and was started on irbesartan $150 \mathrm{mg}$ one oral tablet daily (1-0-0). After 6 months, this dose was reduced to half a tablet which he continues to take to this day. He was also diagnosed with type two diabetes mellitus for which he is actively treated with metformin $1500 \mathrm{mg}$ (1-1-1) daily.

The patient noticed subtle skin changes in 2019 and upon seeking medical advice, he was diagnosed with an incidental finding of low grade papillary urothelial carcinoma, (T1 N0 M0). He was subsequently treated with transurethral surgical interventions and hospitalised for four different sessions before being sent to our dermatological clinic for evaluation of the skin condition. On examination, multiple large psoriasiform plaques were observed bilaterally, predominantly on the trunk, upper and lower extremities (Figure A-D), the greatest measuring approximately $6 \mathrm{~cm}$ in diameter. The plaques were variable in size and polymorphic in nature exhibiting a salmon-pink discoloration. There were no signs of pruritis or poikilodermatous changes. Based on the clinical data, a drug-induced parapsoriasis was suspected. Histopathological examination revealed generalised parakeratosis with perivascular lymphocytic infiltrations in the upper dermis. No signs of mycosis fungoides was noted, keeping in line with a clinicopathological diagnosis of large plaque parapsoriasis.

The simultaneous development of several tumour diseases after starting treatment with sartans is neither new nor rare [1]. The recent increase in such clinical observations stems mainly from geographical areas with reduced drug control in determining the absence/presence of nitrosamines in angiotensin receptor blockers [2]. It is this fact that most likely underlies the boom of the so-called "regional cancer epidemics", which are characterized by the simultaneous but also gradual manifestation of diverse types of tumours, including skin cancers [1-3]. The so-called dose-dependent time intervals required for the development of various skin cancers should not be overlooked [3]. It is exactly these data that should be seriously analysed in the near future in order to clarify the circumstances of co-developing tumours/ cancers[3].

The relationship between neoplastic skin diseases after the application of sartans dates back to 2015/16 on the basis of serious large-scale retrospective analyses in Europe and America $[4,5]$.

At that time (2015/16) the issue of nitrosamines was neither relevant nor known, but the shared statistics were clear and indicative in favour of a serious risk in terms of the development of melanocyte and non-melanocyte cancers after the use of sartans $[4,5]$.

Nitrosamines have been considered to be well known and very potent carcinogens that may produce cancer in diverse organs and tissues including lung, brain, liver, kidney, bladder, stomach, oesophagus, and nasal sinus[6].

The presence of up to 3 carcinogens in the form of nitrosamines in one tablet for high blood pressure/ in sartans is in fact an indisputable fact, repeatedly established, but clearly established repeatedly and currently by the control authorities in the face of EMA [7]. In practice, the EMA cannot allow the presence of carcinogens in sartans that have not been already identified, as this would mean that they have to be added from now on?

Precisely because of this, the inclusion of another prelymphoma/ precancerous skin condition (re-emerging after starting treatment with sartans/ potentially contaminated with nitrosamines) in the face of the large-plaque parapsoriasis to the group of severe adverse medicamentous reactions should not follow in any way to prove problematic or questionable.

The following circumstances are currently worrying:

1. The EMA initially withdraws from the European market all nitrosamine-affected products related to sartans, and two years later attempts are made to legalise nitrosamines as an integral part of any medicinal product designated as sartan regardless of country of manufacture of the active substance [7]?

To what extent the admission of minimum concentrations of one to 3 nitrosamines in one pill would be perceived as an adequate response by patients is and remains unclear. Until recently, 

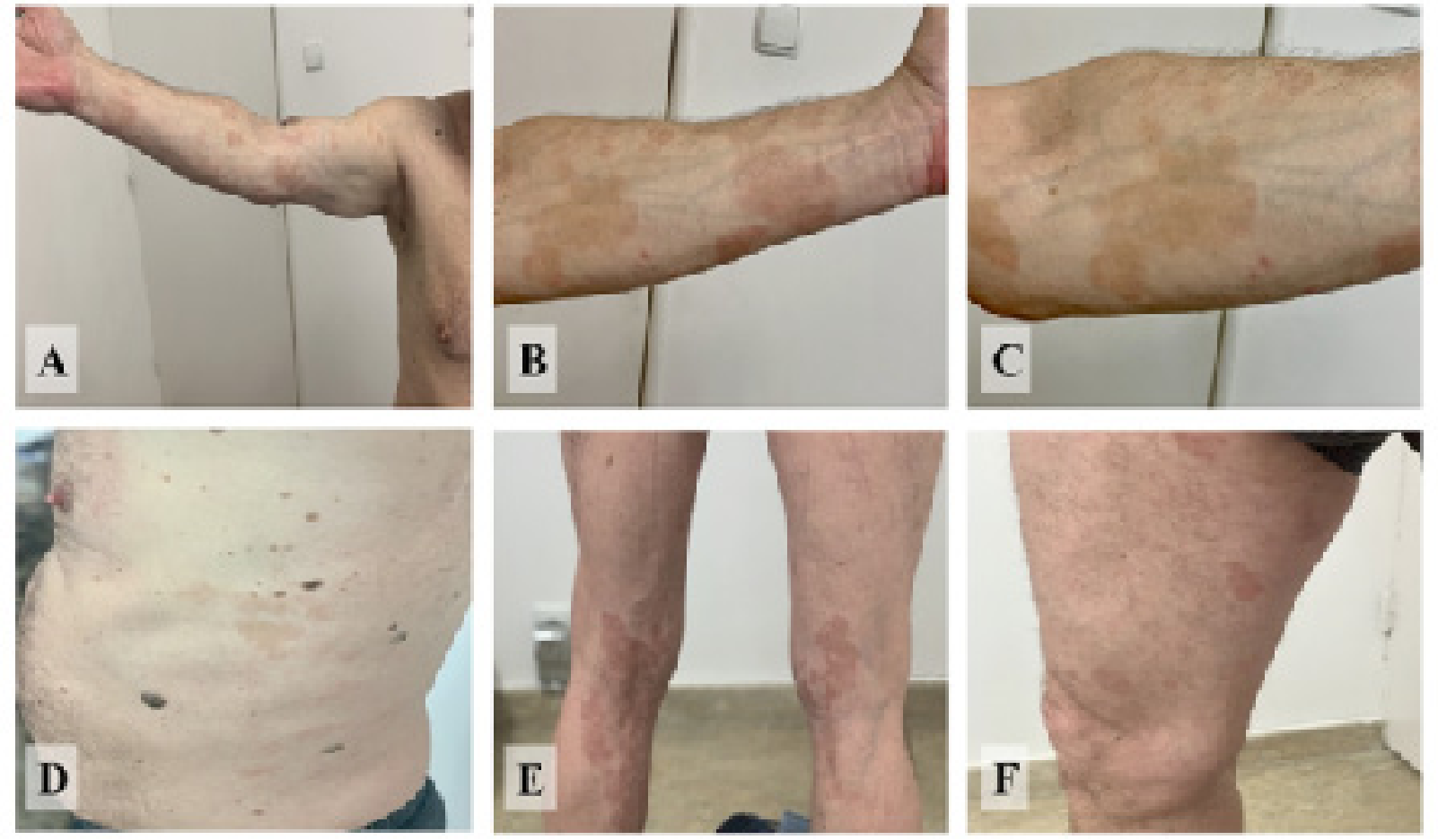

Figure 1: Multiple variable sized and polymorphic psoriasiform plaques on the upper extremities (Panel A, B and C) as well as the trunk (Panel D) and lower extremities (Panel E and F). Morphologically, the plaques were salmon-pink colour with no signs of crusting or scaling. No erythema or other signs of inflammation was noted. Patient did not report any signs of pruritus.

information from the EMA postponed emphatically that only batches from India and China were affected by nitrosamine contamination and that the latter should be withdrawn [8]?

2. The blocking or neglect of the signals by the control authorities themselves at regional and international level, leads to reduced awareness of the patients themselves and subsequent manifestation of multiple and heterogeneous tumours. This practice does not contribute to the crystallization of this important issue.

Finally, a patient who developed the large plaque form of parapsoriasis and urothelial carcinoma after irbesartan therapy is presented. According to the medical literature, this is the first patient described with a similar or such severe medicamentous adverse drug reaction. The role of nitrosamines as a potential inducer of both neoplastic diseases is discussed.

\section{References}

1. Tchernev G, Poterov G. Drug induced cancers: Simultaneously development of cutaneous melanoma, Colon carcinoma and Kaposi Sarcoma under Valsartan/Hydrochlorothiazide. Clin Res Dermatol Open Access. 2020;7(4):1-8.

2. Tchernev G, Poterov G. Antihypertensive drugs and cancer: Simultaneously development of chorroidal melanoma and colon carcinoma after administration with Valsartan/Hydrochlorothiazide. Clin Res Dermatol Open Access. 2020;7(4):1-4.

3. Tchernev G, Bitolska A, Patterson JW. Telmisartan (and/or nitrosamine) - induced occult melanoma: first reported case in world literature. Expert Rev Clin Pharmacol. 2021;10:1-6.

4. Schmidt SA, Schmidt M, Mehnert F, Lemeshow S, Sorensen HT. Use of antihypertensive drugs and risk of skin cancer. J Eur Acad Dermatol Venereol. 2015;29(8):1545-1554

5. Sable K, Majewski S, Nardone B, Cices A, West DP, Laumann AE. Association of melanoma and nonmelanoma skin cancer with antihypertensive drugs: A report from the Research on Adverse Drug events and Reports project. Poster 3167. J Am Acad Dermatol. 2016;74(5):AB221.

6. Robles. Nitrosamines. Reference module in Biomedical Science/ Encyklopedia of Toxicology. 2014;584-585.

7. Sartans medicinal Porducts: EMA`s Assesment Report defined Nitrosamine Limits and reporting Deadlines.

8. Tchernev G, Temelkova I. Valsartan Induced Melanoma?! First Description in Medical Literature! Open Access Maced J Med Sci. 2018;6(12):2378-2380. 